\title{
Commentary: Move fast and break things
}

\author{
Craig R. Smith, MD
}

\footnotetext{
From the Department of Surgery, Vagelos College of Physicians \& Surgeons, Columbia University, New York, NY; and Columbia University Irving Medical Center, New York-Presbyterian Hospital, New York, NY. Disclosures: Author has nothing to disclose with regard to commercial support.

Received for publication Feb 4, 2019; accepted for publication Feb 4, 2019; available ahead of print March 11, 2019.

Address for reprints: Craig R. Smith, MD, Columbia University Irving Medical Center of New York-Presbyterian Hospital, Milstein Building 7-435, 177 Fort Washington Ave, New York, NY 10032 (E-mail: crs2@cumc. columbia.edu).

J Thorac Cardiovasc Surg 2019;158:1331

0022-5223/\$36.00

Copyright (C) 2019 by The American Association for Thoracic Surgery

https://doi.org/10.1016/j.jtcvs.2019.02.034
}

In this issue of the Journal, Allen and colleagues ${ }^{1}$ report a substantial multicenter experience with valve-in-valve transcatheter aortic valve replacement, augmented by bioprosthetic valve fracture (BVF). The hard outcomes (low mortality, good valve hemodynamics) constitute a significant contribution, as well as an important proof of concept for BVF. Not content with that alone, Allen and colleagues ${ }^{1}$ performed an elaborate statistical analysis, which generated 2 practical recommendations that were based on statistically significant differences in multivariable analysis: (1) perform BVF after valve-in-valve deployment of the transcatheter valve, and (2) use a large balloon.

The use of a large balloon makes intuitive sense. Why performing BVF after valve deployment might be superior is not equally intuitive, but Allen and colleagues ${ }^{1}$ provide a reasonably compelling rationale in their discussion section. Nonetheless, it is worth asking whether technical recommendations at this level of detail should drive practice, whether supported by statistical significance or not, when they are based on only 75 patients, from 21 centers, with an unspecified number of operators, with 2 transcatheter aortic valve replacement valve types used in 7 varieties of surgical valves in multiple sizes. Only 9 patients $(12 \%)$ were treated with BVF before deployment. We are not told whether the volume of BVF before deployment procedures, or volume in general, clustered by center or operator. It would be reassuring to know that these 75 cases were consecutive. On that point, Allen and colleagues ${ }^{1}$ say that "efforts were made" to ensure that the cases were consecutive. Dust off the trophy for trying!

In their discussion section, Allen and colleagues ${ }^{1}$ mention an evolving belief that gradients are lower after valve-in-valve replacement when the transcatheter valve is placed "high" or in a supra-annular position. I have a concern that this strategy has the potential to crowd the sinuses, increasing the risk of coronary occlusion. On the

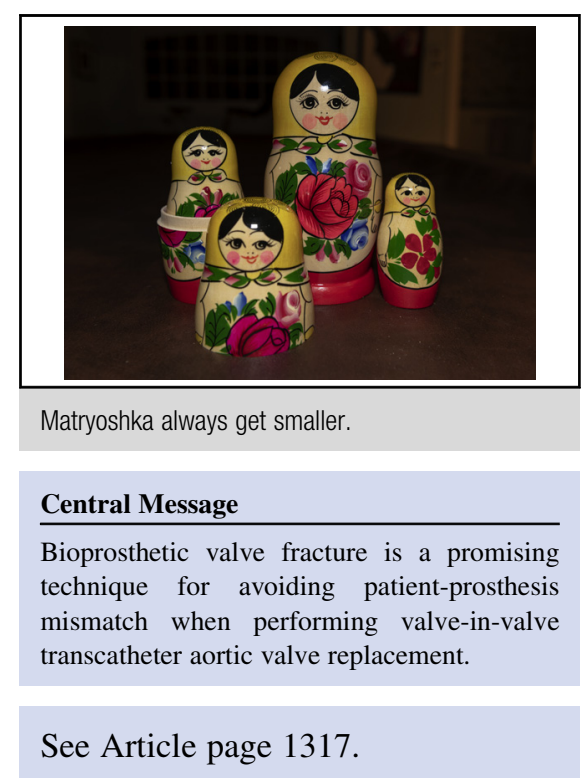

basis of personal experience and broad word-of-mouth, coronary ostial occlusion is a real but aggressively underacknowledged hazard of supra-annular surgical valves, one that might be duplicated with a supra-annular approach to valve-in-valve replacement. It also seems possible this hazard would be increased by the inability to position the transcatheter aortic valve replacement valve radially such that the nadir of each leaflet is at the nadir of each coronary sinus, which is the radial orientation of any surgical valve being treated with valve-in-valve. How often will the transcatheter valve-in-valve place the commissural height of the new valve in the middle of a coronary sinus? This is less of an issue, perhaps, with intra-annular placement.

BVF fractures the circular metal at the ventricular end of the valve, but it depends for more than trivial expansion on straightening the wire that defines the 3 sinuses and 3 posts of a surgical valve. It seems likely that the mechanism would lower post height but increase post width, which might also contribute to sinus crowding. This is a purely theoretic concern at this stage of our understanding.

\section{Reference}

1. Allen KB, Chhatriwalla AK, Saxon JT, Cohen DJ, Nguyen TC, Webb J, et al. Bioprosthetic valve fracture: technical insights from a multicenter study. $J$ Thorac Cardiovasc Surg. 2019;158:1317-28.e1. 